We appreciate the response to this publication feature - and weicome all A contributions. Contributions may be sent to Phil Oshel, our Technical Editor At:

Mr. Phil Oshel
Station A
PO Box 5037
Champaign IL 61825-5037

or by eMail: poshel@hotmail.com

Please note new eMail address

\section{Preparing Gels for Cross-Sectioning}

I have done many "weird" culture specimens, such as collagen gels with cells, gelatinous substances with organoids, trans-well inserts. and more. Some of them were a layer of cells on a gel.

When I prepare these specimens for processing, I lay them flat between two layers of 2 inch square lens paper, wet with formalin. I then place them in a stainless-steel round processing capsule (other kinds would work-MT). Fix, put in the tissue processor (if used), and use the same times and steps as are used for ordinary tissues. Any routine process, either automated or by hand, will work.

Then the fun part comes: embedding.

1) Remove the 2 layers of lens paper with specimen and lay it on the heated platform of my embedding center.

2) Remove the top piece of lens paper and pour a little "puddle" of t. molten wax on the cooling plate (not on the specimen). The wax will start to solidify.

3) Using a small (cooking type, narrow) heated spatula, quickly invert the lens paper-gel sandwich, with the gel towards wax "pancake", and A touch the specimen to the solidifying wax puddle. It will adhere to the t. somewhat molten top of the "pancake".

4) Let the pancake solidify and make one or two cross cuts with a single-edge razor blade.

और 누 well.

南

There are now 2 or 3 pieces to embed on edge. This really works

I have done immunostains as well as special stains on these specimens, so there are many staining options. If there are specific questions, please feel free to e-mail me directly.

\section{Mary Vaughan, Roswell Park Cancer Institute mvaughan@sc3102.med.buffalo.edu}

Note: this method would work for any gel or polymer, aqueous or not, that is not sensitive to the low heat needed to melt the wax (about $60^{\circ} \mathrm{C}$ ). For materials specimens, the fixation steps can likely be discarded, since those are for cells or biological specimens. If the gel or polymer is not aqueous, and either dry or in a solvent miscible with wax, the dehydration and transitional fluid steps necessary for biological specimens can be discarded.-Phil Oshel

\section{Electropolishing of $\mathrm{Cu}, \mathrm{Ni}, \mathrm{Al}$ alloy}

A simple electrolyte that can be used at room temperature for jet polishing various copper alloys for TEM.

$25 \%$ phosphoric acid

$25 \%$ ethylene glycol

$50 \%$ distilled water

\section{Electrothinning:}

Temperature: $20^{\circ} \mathrm{C}$

Voltage: 40 volts

Time: less than 2 minutes to thin a $3 \mathrm{~mm}$ disk from $0.38 \mathrm{~mm}$ to 0.125 $\mathrm{mm}$.

Electropolishing (Used a Tenupol 3 from Struers):

Temperature: $20^{\circ} \mathrm{C}$

Voltage: $14-18$ volts

Current: $150-200 \mathrm{~mA}$

Time: less than a minute to obtain a small hole. Rinsing:

1) Rinse the lollipop in methanol, then remove the specimen

2) Rinse the specimen in 4 separate baths of distilled water

3) Final rinse in ethanol.

I used the electrolyte to electrolytically thin and electropolish a variety of copper alloys, but most of my work was conducted on $\mathrm{Cu}-\mathrm{A}_{2} \mathrm{O}_{3}$. CuNiBe, $\mathrm{Cu}-\mathrm{Ni}$, and $\mathrm{Cu}-\mathrm{Mn}$ alloys.

The reason for using the electrolyte is that the specimens being prepared were radioactive, and the work was done inside a fume hood. Consequently, to avoid any unnecessary exposure to the radioactive specimens and contaminated equipment. it was advantageous to use a room temperature electrolyte, something that didn't require a lot of set up or clean up time.

The only problem l've had recently is getting all of the electrolyte off of the surface; I have found that my rinsing procedure is not completely effective in removing the residual phosphorous from the polished surface.

\section{Dan Edwards. Battelle Pacific Northwest National Laboratory}

\section{Hints For Fixing Vertebrate Eyes}

In my experience (up to 6 eyes per week for about 10 years), the globes MUST be properly fixed. I learned this the hard way, when I was a Medical Technologist, in charge of the Neuropathology Laboratory at the University of Cape Town Medical School, Anatomical Pathology Department.

We would 'lop' off the 'top' and the 'bottom' - like a breakfast soft boiled egg - after 21 hours in $10 \%$ buffered formalin. The cuts are made in line with the cornea after orienting the specimen properly. The inferior and superior pieces were processed routinely overnight if properly fixed - with excellent results.

The roughly $8 \mathrm{~mm}$ thick mid-portion should be handled according to the contents of the globe - sometimes another 24 to 48 hours fixation is necessary for tumor or blood filled globes, particularly if the tumor is necrotic.

Thereafter a long dehydration program is required:

3 changes of absolute alcohol, total time about 8 or 10 hours.

follow with a manual inspection to check for proper dehydration.

6 to 8 hours total in 3 changes of $100 \%$ xylene (or other clearing agent)

ca. 12 hours total in 3 wax changes

embed routinely in paraffin wax.

When sectioning, use lots of ice and section at 4 to 6 micrometers. I used to float out on $10 \%$ alcohol (or weaker) before the warm water bath. My results 